\title{
Jacek Prusik
}

Inżynier

jacrolli@gmail.com

\section{Tomasz Rogalski}

Dr hab. inż.

Politechnika Rzeszowska, Wydział Budowy Maszyn i Lotnictwa,

Katedra Awioniki i Sterowania

orakl@prz.edu.pl

DOI: 10.35117/A_ENG_19_02_04

\section{Automatic removal of the plane from a spin using fuzzy logic controller}

\begin{abstract}
The paper presents a concept of automatic control system recovering an aircraft from the spin using fuzzy logic controller. Control system causing: stall, spin, spin recovery, dive recovery and switching on classic heading and altitude autopilots, was created in Matlab - Simulink software, which was connected to the flight simulator X-Plane. During tests developed control algorithms were checked and tuned. At the end graphs of flight parameters recorded during simulation were analyzed, and properties of designed control system were evaluated. Particular attention was paid to the design of a fuzzy logic controller stopping autorotation of the aircraft. On the output it controlled the position of the rudder, while on input it received a signal being a function of the angular velocity of the aircraft.
\end{abstract}

Keywords: Spin; Automatic control system; Simulation

\section{Introduction}

Classic autopilots are designed to stabilize the flight of an aircraft in the steady state. The system discussed in this article is significantly different from the systems used in modern aircraft.

At the outset, it should be noted that a different from the classical [1, 4] approach to autopilot design was adopted $[2,8,9]$, which made it possible to abandon the use of advanced mathematical models of airplane flight in states of disturbed flight [4]. In addition, the state of the flight, which is a spin, is characterized by variable dynamics of the aircraft resulting from the range of flight speed changes. The task of the control system was in the first place to lead to the stall of the plane $[3,7]$ while maintaining stabilization of the angle of tilt and flight altitude. The spin itself from the point of view of automation is an atypical state of flight, because in its course a sudden change of all state variables occurs, both in the longitudinal and lateral movement. However, this is a phenomenon that can be certain that it will occur under certain conditions, for example when a plane flying with an angle of attack [7] close to the critical one is affected by an atmospheric disturbance or purposeful operation of the controls.

The mathematical program Matlab developed with the Simulink computer simulation package was the tool used to design the discussed control system. The testing stand for testing hardware-in-the-loop-simulation was used to test the resulting system [10]. It uses the XPlane flight simulator communicating with Matlab via UDP transmission. This solution has been repeatedly used in scientific works to check the operation of designed autopilot systems $[6,11]$.

In this work, the system of automatic spin maneuver described in item [7] was used and introduced in it a modification involving the use of the fuzzy logic controller in the sequence responsible for stopping the autorotation of the aircraft. 


\section{Assumptions concerning the air maneuver}

\section{The aircraft as a control object}

The control object is an airplane in the classical configuration [1,3]. Control of its spatial orientation is done by tilting the rudder planes generating force moments around the XYZ axis, the coordinate system associated with the plane. Its origin lies in the center of gravity of the plane and the axes are directed towards the front respectively - the X-axis, the right wing the Y-axis and down - the Z-axis (Fig.1). To determine the spatial orientation of the aircraft with respect to the earth's surface, Euler angles describing the mutual orientation of the system related to the plane and the system - OXeYeZe (Figure 1) are used. Its origin is also in the center of gravity of the plane, but its Xe and Ye axes are parallel to the surface of the earth $[1,3]$

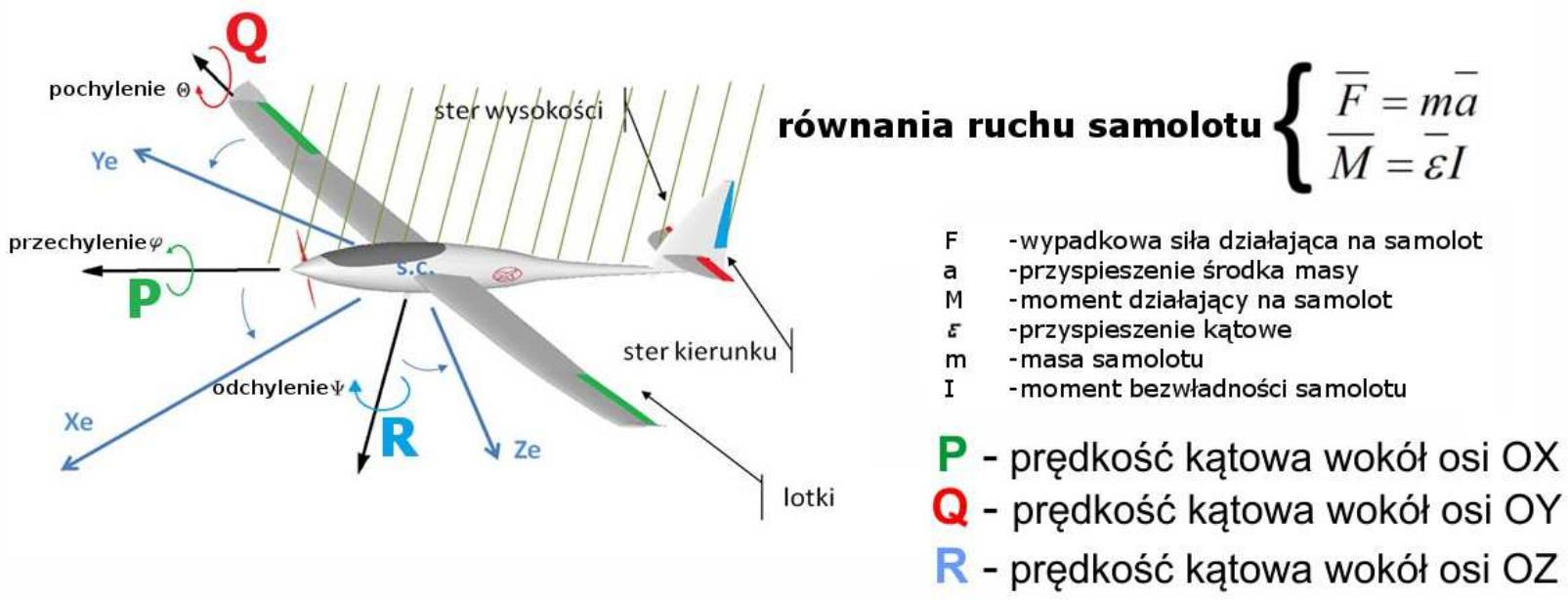

1. Control of the spatial orientation of the aircraft

\section{The spin}

The flight mechanics describe a spin, as a flight condition, and an autotoxic [7] aerobatics figure performed at larger critical angles of attack. When the disruption of the plane is triggered (motion by the rudder or by a sudden blast), it will deepen its inclination while leaning towards it. The tilting is caused by the difference of bearing forces on the wings, and the deviation - by the difference of resistance forces and force on the vertical tail.

The spin is seen as a motion in which the center of gravity of the plane outlines a characteristic spiral-shaped path that forms the boundary of the cylinder.

From the point of view of the rules of piloting, moving the aircraft out of the spin state is the most difficult phase of the discussed maneuver. Its basis is to stop the phenomenon of autorotation. It is a maneuver performed by the pilot according to the principles developed experimentally. Sometimes, the exit procedure is individually developed. In any case, you can extract the following standard procedure for removing an airplane from a spin:

1. close the throttle,

2. set the ailerons in the neutral position, at the same time the elevator in the position ensuring speed recruitment,

3. check the direction of autorotation,

4. deflect the rudder in the opposite direction to autorotation,

5. wait until the autorotation disappears, 
6. lead out gradually from the dive, taking care not to exceed the construction limitations of the aircraft.

\section{Simulation station}

The simulation test stand has been integrated based on the MATLAB environment and XPlane software [6].

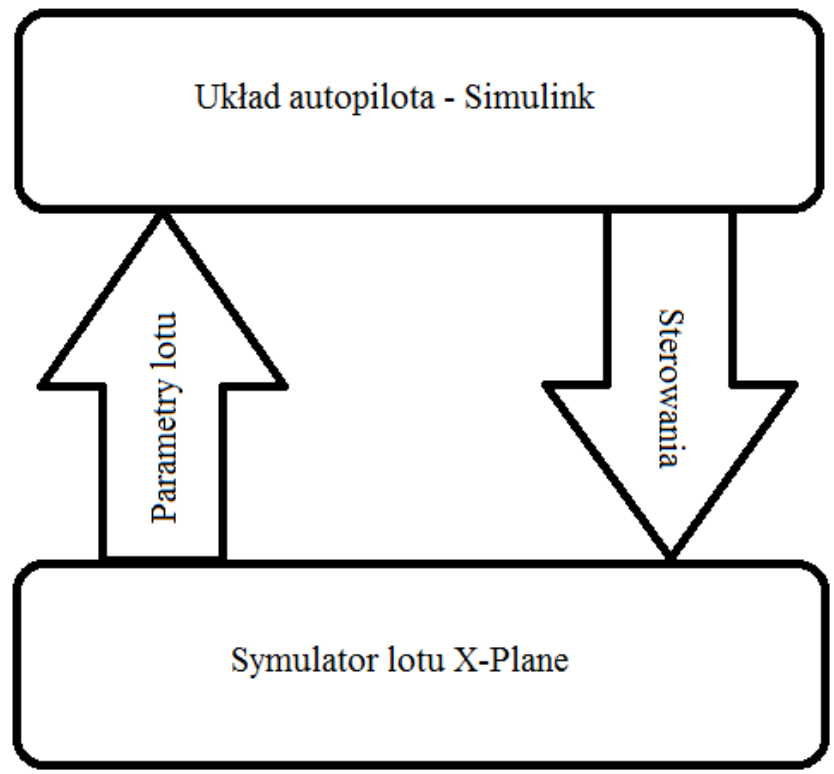

2. Block diagram of data exchange between a flight simulator and autopilot

The designed control system, whose operation was simulated in the MATLAB environment, through UDP transmission controlled the airplane model implemented in the XPlane software. With the same channel, the values of flight parameters of the aircraft were sent to the autopilot by closing the feedback loop.

\section{Design methodology}

\section{The synthesis of control laws has been based on the following assumptions:}

Assumption 1: The controller stopping the autorotation is automatically switched on and its operation lasts from the time the spin is made, set by the user to obtain a low angular velocity of the aircraft, indicating the stopping of autorotation.

Assumption 2: Due to the fact that the spin is a phenomenon related to the rotation of the aircraft in relation to all axes of the reference system, the measurement of the angular velocity module of the aircraft was used to detect the autorotation stoppage |PQR

Assumption 3: The fuzzy logic controller receives the value of the angular velocity $\mathrm{R}$ on the input and calculates the signal controlling the rudder of the direction.

According to the assumptions described in item [7], the spinning process was divided into phases, each of which will be performed by a separate control sequence. The whole process will proceed as shown in the diagram (Figure $\mathbf{3}$ ).

After the spin was made for the time set by the user, the system was switched to the next sequence that leads the plane out of the spin state. Basically, this is done by pivoting the rudder in the opposite direction to autorotation.

The termination of the derivation from autorotation was equivalent to the plane's achievement of appropriately low angular velocities P, Q, R (Figure 1). Since the spin is a 
phenomenon related to rotation relative to all axes (1), the angular velocity module of the aircraft was calculated:

$$
|P Q R|=\sqrt{P^{2}+Q^{2}+R^{2}}
$$

- P-angular velocity relative to the OX axis,

- Q- angular velocity relative to the OY axis,

- $\mathrm{R}$ - angular velocity relative to the $\mathrm{OZ}$ axis.
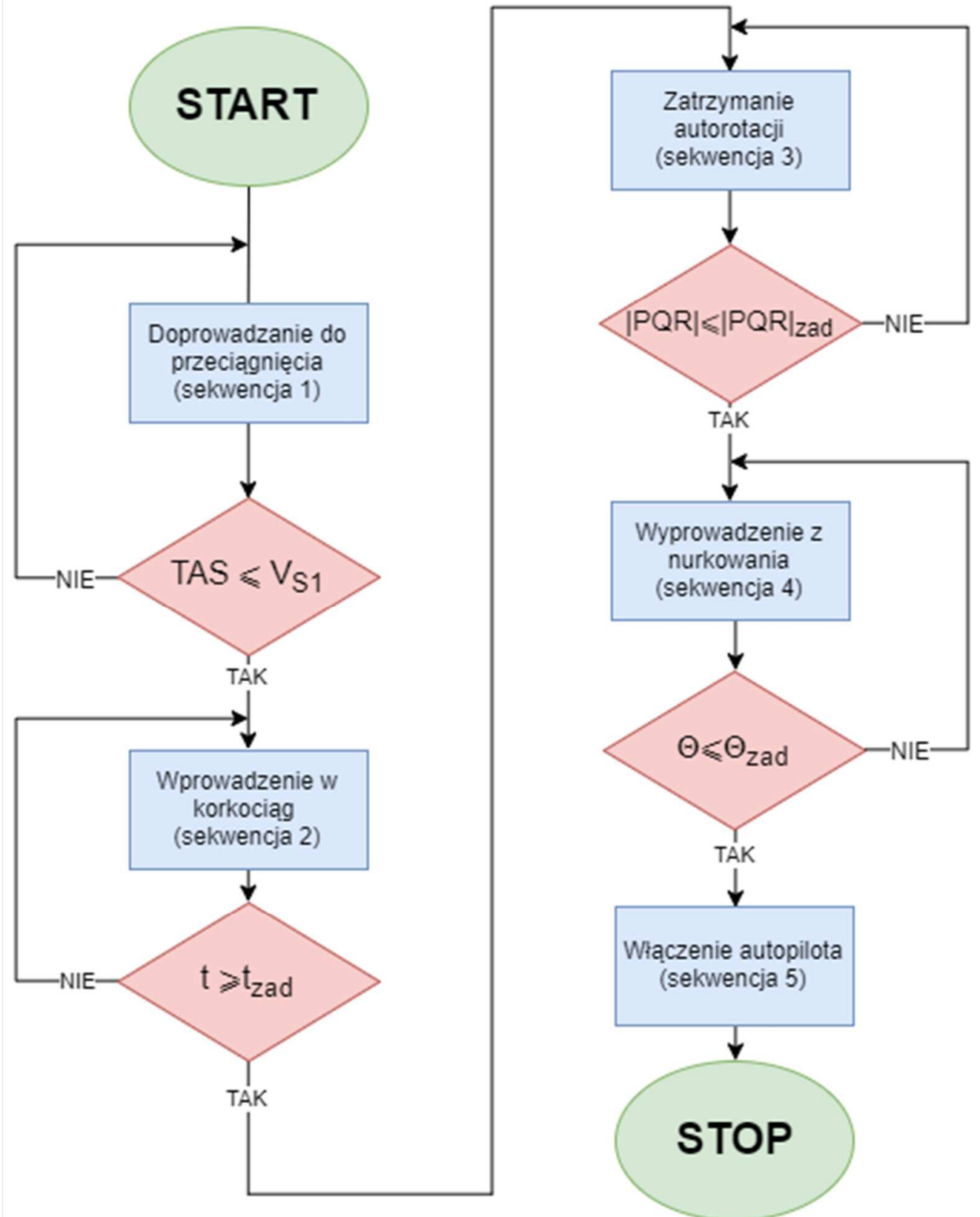

3. Block diagram (decision-making) of the function switching the control sequences in the subsequent phases of the maneuver

The value of the calculated module was compared with the set value, previously determined experimentally so that after switching off the regulator there was no autorotation phenomenon, and the plane was in a steep descent. The adopted method is the most general check of the angular velocity values of an airplane when it comes out of a spin In this phase, the ailerons remained in the neutral position (2). 
$d A(t)=0$

$\mathrm{dA}(\mathrm{t})$ - Ailerons

while the altitude control in the position ensuring safe and effective passage to the diving flight after stopping autorotation. In the case of most aircraft in a classic arrangement, the position is neutral (3)

$d H(t)=a_{H}$

$\mathrm{dH}(\mathrm{t})$ - High Control/ Elevator,

$\mathrm{a}_{\mathrm{H}} \quad$ - constant value resulting from the characteristics of the aircraft.

The main purpose of this work was to design a fuzzy logic controller controlling the rudder in such a way that the autorotation was stopped in a similar way to the pilot, i.e. the rudder deflection is to decrease with decreasing angular velocity of the aircraft. The Fuzzy Logic Designer package available in the Matlab environment was used for the regulator's design.

According to the assumptions, the regulator on the input receives the value of the angular velocity of the $\mathrm{R}$ deflection. These values have been divided into the compartments shown in Figure 4:

- "negative": [-720; -150;0] [ $\square / \mathrm{s}]$,

- "close to nil": [-150;0;150] [ $\square / \mathrm{s}]$,

- "positive": [0; 150; 720] [ $\square / \mathrm{s}]$.

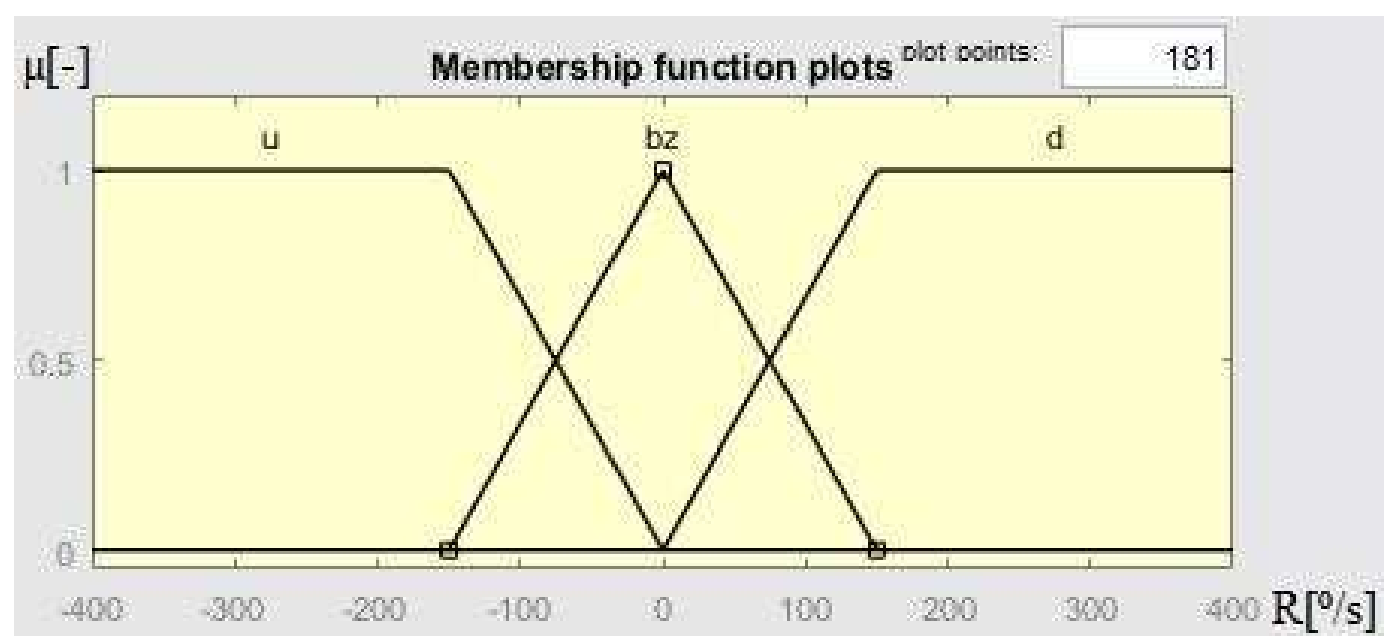

4. RV angular velocity ranges (printout from the Matlab-Simulink program)

Next, the control intervals generated by the controller are defined. The X-Plane flight simulator operates with the sweeps of all rudders in the range of $[-1 ; 1]$, therefore those from the range $[-0.2 ; 0.2]$. The remaining control values have been assigned to the "negative" collections:[0;0.2;1] and "positive": $[-1 ; 0,2 ; 0]$. 


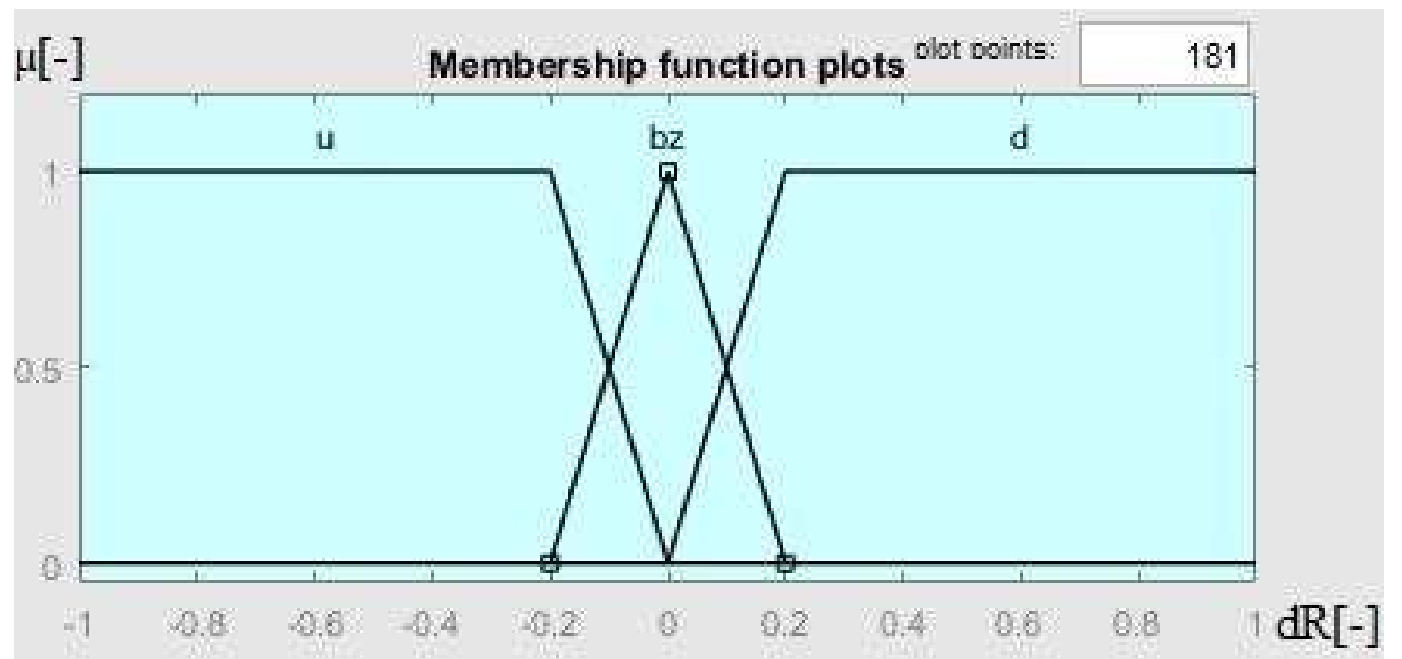

5. Range of rudder deflection values $d R$ (printout from the Matlab-Simulink program)

The membership functions have been selected so that the rudder is tilted in the opposite direction to the direction of autorotation. Thus, if, for example, the autorotation has a positive direction (to the right), the rudder should be pivoted to the left ("negative" interval). The angular velocity of the deflection decreases, gradually entering into the "close to zero" compartment with increasing membership. These functions represent the following record:

- if ( $R$ is $u)$ then ( $d R$ is $d)$ - if the speed $R$ is negative (rotation to the left), then the rudder is turned to the right,

- if ( $\mathrm{R}$ is bz) then ( $\mathrm{dR}$ is bz) - if the speed $\mathrm{R}$ is close to zero, then the rudder stays in a neutral position,

- if ( $R$ is $d$ ) then ( $d R$ is $u$ ) - if the speed $R$ is positive (rotation to the right), then the rudder is turned to the left.

\section{Sample simulation results}

\section{Control signal}

After the simulation was performed, the analysis of changes in the value of the signal controlling the rudder of the direction sent to the aircraft model was carried out. In order to illustrate the relationship between the deflection of the rudder and the angular velocity of deflection, the time courses of both variables are shown in one graph in Figure 6. 


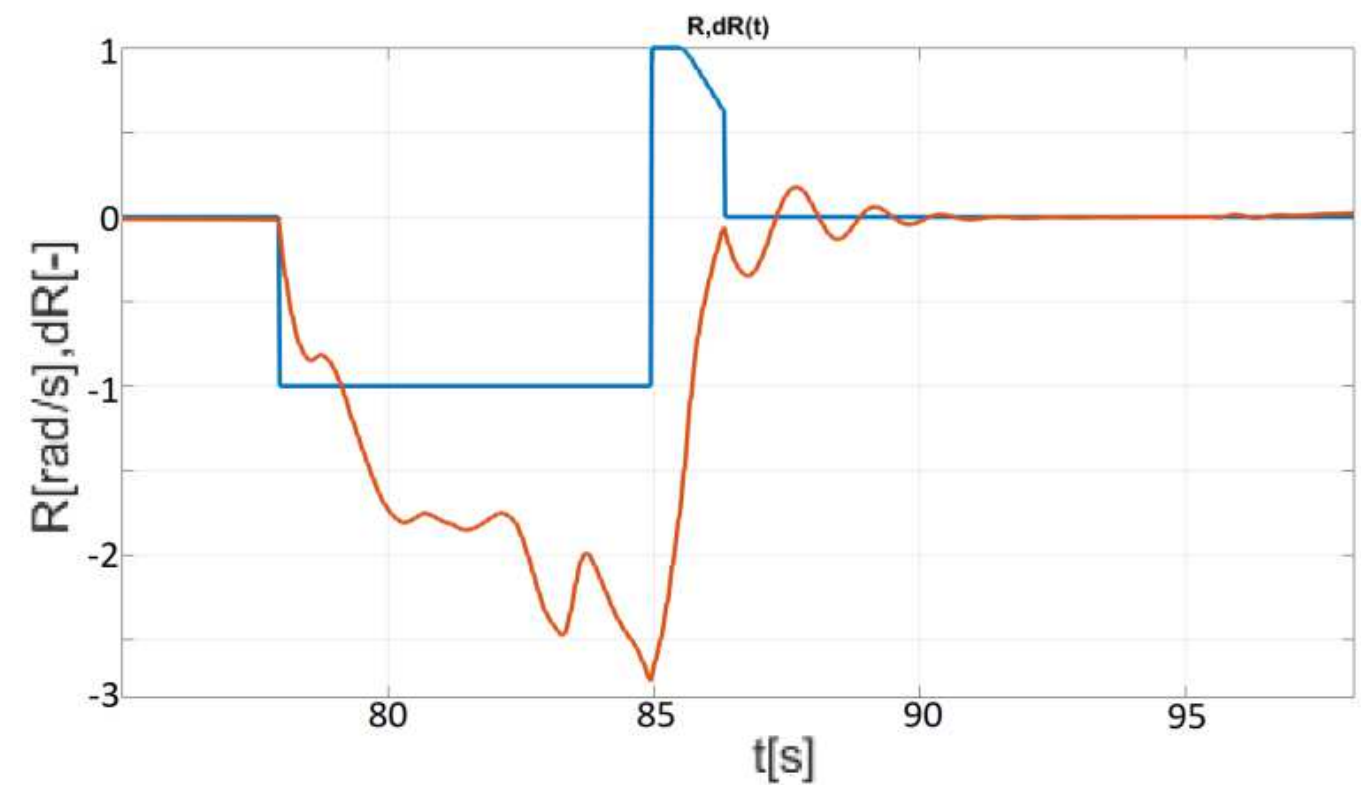

6. Controling rudder control $\mathrm{dR}$ (blue color) and angular velocity $\mathrm{R}$ (orange color)

Steering rudder control results indicate that the aircraft model has reached the stall speed in the 78-second simulation. At this point, he was put into a spin. Performing the maneuver took 7 seconds in accordance with the parameters set by the user. The derivation sequence from autorotation was included in the 85-second simulation and lasted for about one and a half seconds. These data are necessary for the analysis of subsequent graphs related to changes in angular velocity values.

\section{Angular velocity}

One of the most important analyzes concerns angular velocity changes $|\mathrm{PQR}|(\mathrm{t})$. The use of the parameter allowed to analyze the spin maneuver and determine whether the adopted method of detecting the departure of the aircraft from autorotation is correct.

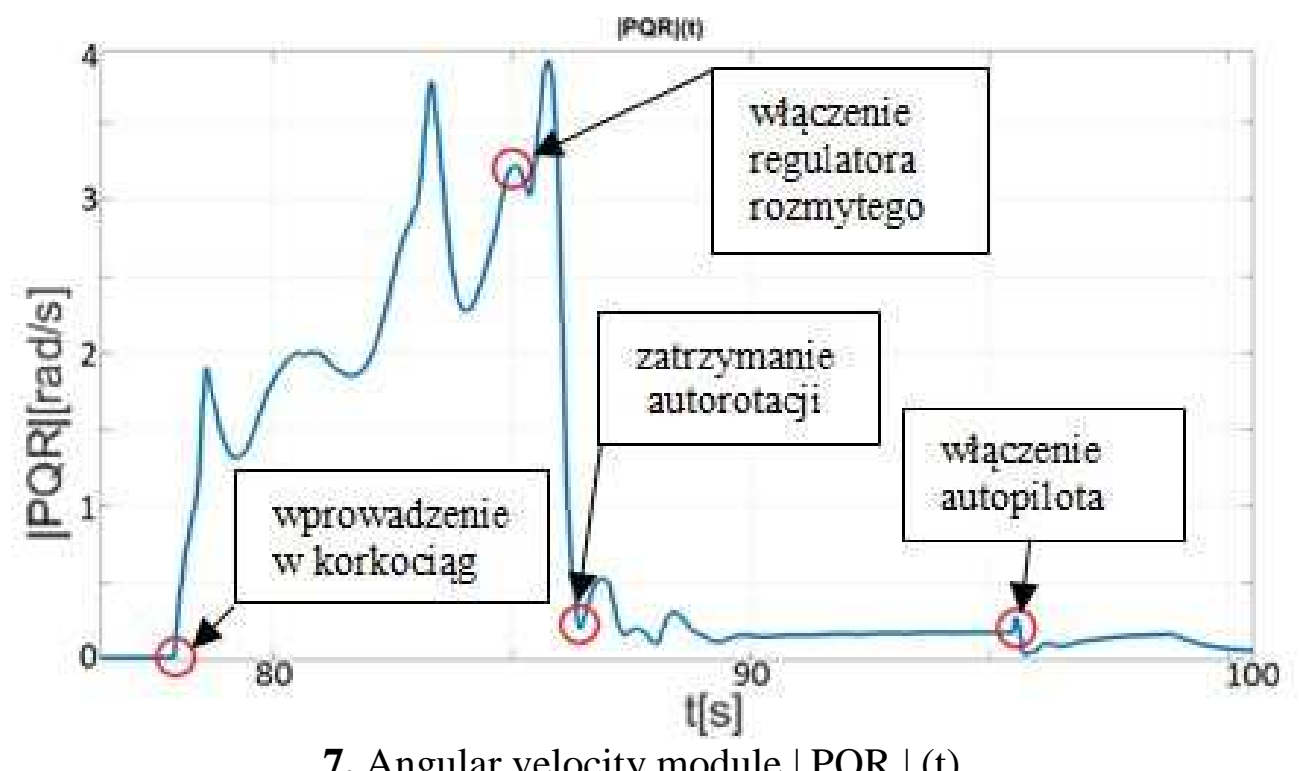

7. Angular velocity module $|\mathrm{PQR}|(\mathrm{t})$ 
Diagram | PQR | (t) - Fig. 7 indicates that at the moment of spinning (about 78 seconds) the angular velocity module increases rapidly. On the other hand, it disappears when autotuning stops, to assume a value close to zero after entering the plane into a fixed flight of levels.

It can, therefore, be concluded that the adopted criterion for stopping the autorotation described earlier is correct because the spin is a phenomenon related to the rotation of the aircraft in relation to all three axes.

In order to illustrate the course of the maneuver being performed, a graph is presented in Figure 7 showing the individual angular velocities of the aircraft. The colors are marked:

- red - angular velocity of tilting $\mathrm{P}$,

- blue - angular velocity of tilt Q,

- black - angular velocity speed R.

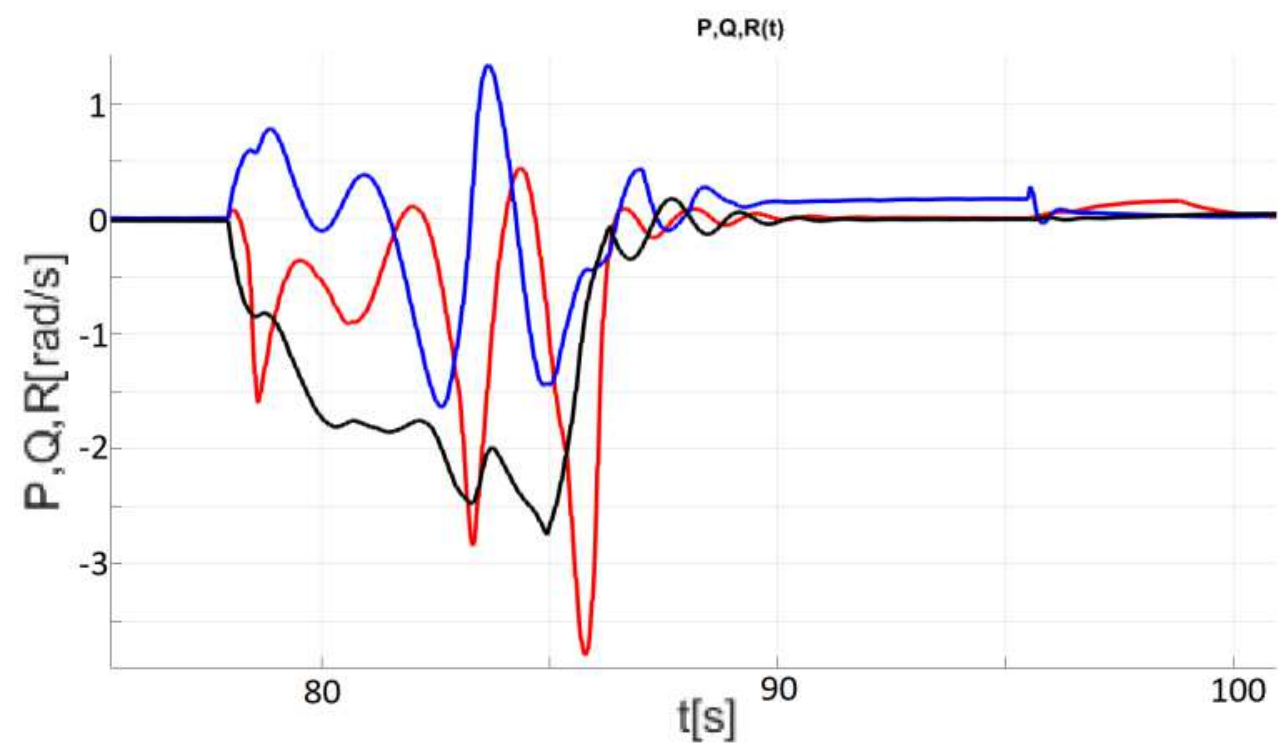

8. Mileages of angular velocities $P, Q, R(t)$

It can be seen that when the spin is introduced, a rapid increase in all angular velocities takes place, and the largest share in the total angular velocity of the aircraft rotation has an angular velocity of deflection. It can, therefore, be considered as an input to the fuzzy logic controller as correct. It is worth paying attention to the fragments of the graphs $|\mathrm{PQR}|(\mathrm{t})$ and $\mathrm{P}, \mathrm{Q}, \mathrm{R}(\mathrm{t})$ in the time interval $[85 \mathrm{~s} ; 87 \mathrm{~s}]$. When the regulator is switched on, it can be seen that initially, the angular velocity module increases despite decreasing the angular velocity of the deflection. This is due to the momentary increase in the angular velocity of tilting in this time interval and results from the dynamics of the aircraft in lateral motion.

\section{Summary}

During the design process, many minor obstacles were encountered ranging from problems with UDP transmission synchronization to flight simulator errors. The solution to these problems allowed us to create a working environment that would allow us to accurately test the dynamics of the aircraft.

The main task of the project was to create and simulate the operation of the fuzzy logic controller to bring the aircraft out of the spin. Particular attention was paid to the selection of appropriate angular velocity ranges, which were adopted after the input variable and the rudder control signal. This operation was complicated by the fact that it was associated with the passage of the plane from a fixed spin to a steep descent, therefore the dynamics was changing, and the process of tuning the regulator was associated with many unsuccessful attempts. Computer simulations were also associated with the current analysis of the entire 
matrix of data displayed on the screen during the experiment. Analysis of state variables during the maneuver led to finding some correlations.

When the plane in a flat, fixed spin is forced to stop autorotation, its angles of tilt and inclination are increased, resulting in the momentary occurrence of angular velocities. However, this does not affect the decreasing angular velocity of the deflection, so it is proof that adopting the angular velocity of the deflection as an input signal to the regulator is a good solution.

One of the conclusions developed during the creation of the discussed system and the simulation is the possibility of applying to the real-time control of the dutch roll damping, switched with the sequence leading the plane out of the dive. Using this method would help to suppress residual oscillations in lateral motion after stopping autorotation and, as a result, create a system to control the aircraft model in a manner more similar to the operations performed by the pilot.

\section{Source materials}

[1] Bociek St., Gruszecki, J. Układy sterowania automatycznego samolotem, Oficyna Wydawnicza Politechniki Rzeszowskiej, Rzeszów, 1999.

[2] Dołega, B., \& Rogalski, T. Control system for medium-sized flying target. Aviation (Vol. 13, pp. 11-16). Vilnius: Technika. doi:10.3846/1648-7788, Vilnius, 2009.

[3] Etkin B. Dynamics of Atmosferic flight, Wily and Sons, Toronto, 1972.

[4] Kaczorek T. Teoria sterowania, PWN, Warszawa, 1981.

[5] Krawczyk, M., Graffstein, J., \& Maryniak, J. Mathematical model of UAV in numerical simulation of the recovery maneuvers during perturbed flight. Journal of Theoretical and Applied Mechanics, 38(1), s.121-130.

[6] Majka M., Rogalski T., Wykorzystanie oprogramowania Matlab do sterowania w czasie rzeczywistym modelem samolotu $w$ symulatorze lotu, monografia ISBN 978-83937270-0-1,, Tomasz M. Majka Publisher, Tarnów, 2014.

[7] Prusik J., Automatyczny system sterowania wprowadzajacy $i$ wyprowadzajacy ze stanu korkociagu, praca dyplomowa pod kierunkiem T. Rogalskiego, Wydział Budowy Maszyn i Lotnictwa, Politechnika Rzeszowska, Rzeszów, 2016.

[8] Rogalski T., Algorytmy sterowania lotem samolotu bezzałogowego w nietypowych stany lotu, Technika Transportu Szynowego 12/2015 ISSN 1232-3829, Instytut NaukowoWydawniczy "TTS" sp. z o. o. Radom, 2015.

[9] Rogalski T., The Control Algorithms for Maneuvering Flying Terget, Scientyfic Aspects of Unmanned Mobile Vechicle, t.1, s. 177-184, Politechnika Świętokrzyska , Kielce 2010.

[10] Rogalski T, Dołęga B:, The New Conception of The Laboratory Testing of the FBW Control Systems for Small Aircraft, Aircraft Enginering and Aerospace Technology: An International Journal No 3, 2004, Emerland 2004.

[11] Samolej S., Orkisz M., Rogalski T. The Airspeed Automatic Control Algorithm for Small Aircraft. In: Nawrat A., Bereska D., Jędrasiak K. (eds) Advanced Technologies in Practical Applications for National Security. Studies in Systems, Decision and Control, vol 106. Springer, Cham, 2018. 